DOI 10.35694/YARCX.2020.49.1.014

ОСНОВНЫЕ НАПРАВЛЕНИЯ ПОВЫШЕНИЯ НАДЁЖНОСТИ РЕЗЬБОВЫХ СОЕДИНЕНИЙ В УЗЛАХ И АГРЕГАТАХ СОВРЕМЕННЫХ АВТОМОБИЛЕЙ

\author{
Б.С. Антропов (фото) \\ д.т.н., профессор, профессор кафедры автомобильного \\ транспорта \\ ФГБОУ ВО «Ярославский государственный технический \\ университет», г. Ярославль

\section{В.В. Капралов} \\ к.п.н., старший преподаватель кафедры тактики \\ и общевоенных дисциплин \\ В.В. Гуменный \\ доцент кафедры тактики и общевоенных дисциплин \\ В.А. Генералов \\ преподаватель кафедры тактики и общевоенных дисциплин \\ ФГБУ МО «Ярославское высшее военное училище \\ противовоздушной обороны», г. Ярославль
}

Надёэнность резьбовых соединений, элементы резьбовых соединений (болты, гайки, шайбы), методы затяжки резьбовых соединений

Reliability of threaded connections, elements of threaded connections (bolts, nuts, washers), methods of tightening threaded connections

Повышение надёжности резьбовых соединений в современных автомобилях очень актуально, т.к. оно наряду с топливной экономичностью и трудоёмкостью ТО является одним из составляющих конкурентоспособности на рынке автомобильной техники в Российской Федерации.

За последние двадцать лет энерговооружённость автомобильной техники возросла примерно в два раза за счёт форсировки двигателей по наддуву. Это обстоятельство предъявляет серьёзные требования к надёжности резьбовых соединений в узлах и агрегатах автомобилей и, в первую очередь, в двигателях, как наиболее подверженных воздействиям знакопеременных силовых и тепловых нагрузок.

В настоящее время широко применяемые в отечественном автостроении такие элементы, как болты, гайки, плоские и пружинные шайбы (шайбы Гровера, изобретённые английским инженером Джоном Гровером во второй половине 19 века), приводят при эксплуатации автотранспортной техники к нежелательному явлению - са- 
моотворачиванию и, как следствие, требуется постоянный контроль состояния резьбовых соединений.

В мировом автостроении идёт процесс прекращения использования пружинных и плоских шайб. Одновременно с этим плоские шайбы изготавливаются как одно целое с болтами и гайками, а их опорные поверхности с контактирующими деталями имеют насечки и рифления с целью исключения самоотворачивания.

Другим методом достижения необходимых характеристик резьбовых соединений является применение гелей и клеев, которые наносятся на поверхности с резьбой, а при контакте с металлом и отсутствии воздуха они полимеризуются, решая таким образом проблему самоотворачивания. За счёт полимеризации достигается герметичность резьбовых соединений, обеспечивается защита резьбы от коррозии, прекращается режим фракционного спекания, а также гарантируется высокая прочность и стойкость к вибрациям (рис. 1) [1].

Недостатком этого метода является тот факт, что фирмы-изготовители автотранспортных средств рекомендуют при ремонте узлов и агрегатов в условиях эксплуатации менять использованные крепёжные элементы на новые.

Рассмотренный метод не применим для ответственных резьбовых соединений в узлах и агрегатах автомобилей и тракторов. Такими соединениями в двигателе являются: болтовые соединения нижних крышек шатунов; крышек коренных опор коленчатого вала; головок цилиндров к блоку. Замена болтов в данных соединениях является нежелательной.

Для указанных креплений разработан метод затяжки болтов в несколько приёмов: первый по крутящему моменту; второй и третий - по углу поворота головки болта. Этот метод прошёл широкие стендовые и эксплуатационные испытания

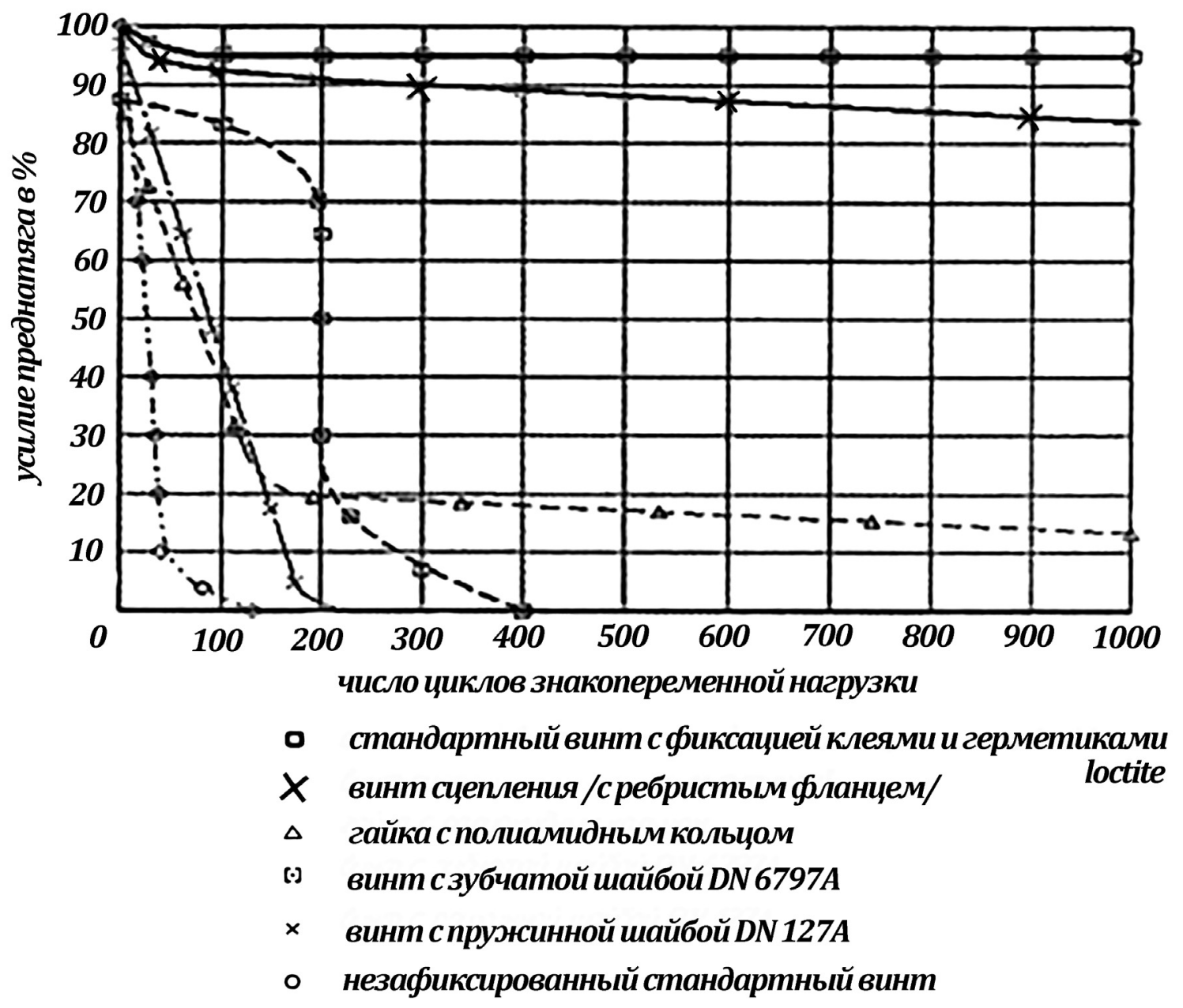

Рисунок 1 - Графики самоотворачивания различных типов фиксации резьбовых соединений 
и показал достаточно высокую надёжность, что позволило фирмам-изготовителям двигателей исключить из руководств по эксплуатации регулярную проверку состояния крепления головок цилиндров к блоку двигателя.

Этот метод внедрён на новых двигателях серии ЯМ3-530, выпускаемых Ярославским моторным заводом. Многоэтапная затяжка болтов крепления головок цилиндров на этих двигателях автоматизирована при их сборке в заводских условиях. В руководстве по эксплуатации двигателей ЯМ3-534 и ЯМ3-536 имеется запись о том, что в процессе эксплуатации автомобилей с указанными двигателями контроль затяжки крепления головок цилиндров не требуется [2, 3]. При ремонте двигателей в условиях АТП рекомендуется затяжку болтов крепления головок цилиндров производить в три приёма после закручивания их от руки:

- первый приём - болты затянуть моментом 100+10 H/м (10+1 кГс/м) с помощью динамометрического ключа, после чего на их головках сделать метки фломастером по металлу, обращённые в сторону впуска;

- второй приём - болты повернуть на $180^{\circ} \pm 5^{\circ}$; - третий приём - болты повернуть на $90^{\circ} \pm 5^{\circ}$.
Порядок затяжки необходимо выдерживать при каждом приёме, как указано схемой в руководстве по эксплуатации.

Другим новым и прогрессивным решением является применение обжимных болтов. Ранее для сборки рам автомобилей применялся, несомненно, надёжный, но не менее затратный метод «горячей заклёпки».

Применение обжимных болтов даёт аналогичные характеристики при меньших затратах по трудоёмкости и оборудованию. В качестве примера можно привести рамы таких грузовиков, как MAN, Volvo, Scania. Эти рамы собраны с помощью таких болтов с обжимным кольцом большого диаметра. На рисунке 2 показан процесс установки обжимного кольца.

Недостатком рассмотренного метода является тот факт, что он применим для соединения только плоских деталей.

\section{Выводы}

1. Изменение геометрии крепёжных элементов и применение клеев и герметиков способствуют повышению надёжности резьбовых соединений автомобиля.
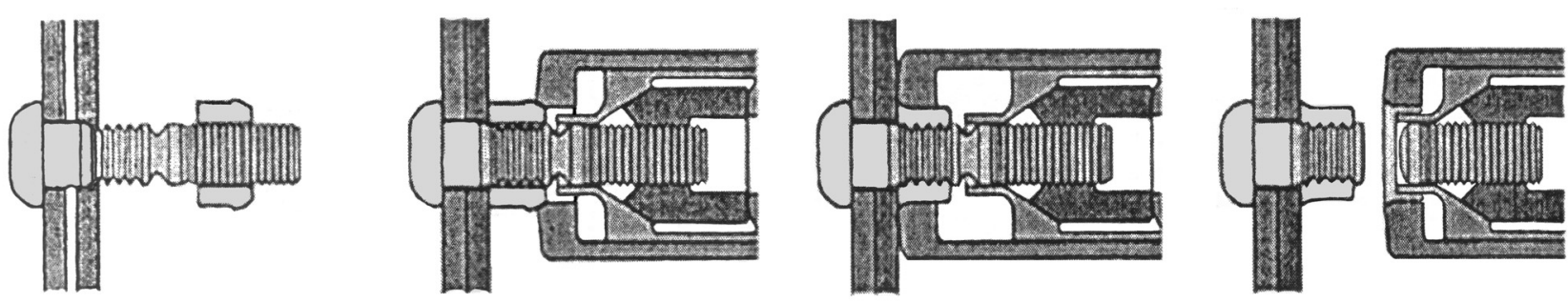

Рисунок 2 - Процесс установки обжимного кольца

2. Применение метода затяжки резьбовых соединений в узлах и агрегатах автомобиля в несколько приёмов (по крутящему моменту и углу поворота головки болта) обеспечивает им высо- кую надёжность по сравнению с методом затяжки только по крутящему моменту, который до настоящего времени применяется в автостроении.

\section{Лumepamypa}

1. Фиксаторы резьбы Loctite (Локтайт) [Электронный ресурс]. - Режим доступа: http://loctite.gluesale. $\mathrm{ru} /$ solutions/threadlock/.

2. Руководство по эксплуатации двигателей ЯМЗ-534 и их модификации. Руководство по эксплуатации 5340.3902150РЭ. - Ярославль: ПАО «Автодизель» (ЯМЗ), 2016. - 160 с.

3. Руководство по эксплуатации двигателей ЯМЗ-536 и их модификации. Руководство по эксплуатации 536.3902150РЭ. - Ярославль: ПАО «Автодизель» (ЯМЗ), 2013. - 240 с. 


\section{References}

1. Fiksatory rez'by Loctite (Loktajt) [Jelektronnyj resurs]. - Rezhim dostupa: http://loctite.gluesale.ru/ solutions/threadlock/.

2. Rukovodstvo po jekspluatacii dvigatelej JaMZ-534 i ih modifikacii. Rukovodstvo po jekspluatacii 5340.3902150RJe. - Jaroslavl': PAO «Avtodizel'» (JaMZ), 2016. - $160 \mathrm{~s}$.

3. Rukovodstvo po jekspluatacii dvigatelej JaMZ-536 i ih modifikacii. Rukovodstvo po jekspluatacii 536.3902150RJe. - Jaroslavl': PAO «Avtodizel'» (JaMZ), 2013. - 240 s.

\section{ОБЫЯВЛЕHИЕ}

В издательстве ФГБОУ ВО Ярославская ГСХА в 2019 году вышло учебное пособие, получивщее гриф Федерального УМО по сельскому, лесному и рыбному хозяйству для обучающихся

по направлению подготовки 35.03.06 «Агроинженерия»

(профиль «Электрооборудование и электротехнологии в АПК»)

«ЛИНЕЙНЫЕ ЭЛЕКТРИЧЕСКИЕ ЦЕПИ»

АвторЫ: В.В. МОРОЗОВ, П.С. ОРЛОВ, В.В. ШМИГЕЛЬ

УЧЕБНОЕ ПОСОБИЕ СОДЕРЖИТ СВЕДЕНИЯ, НЕОБХОДИМЫЕ ДЛЯ ФОРМИРОВАНИЯ ПРОФЕССИОНАЛЬНЫХ КОМПЕТЕНЦИЙ ПРИ ПОДГОТОВКЕ БАКАЛАВРОВ ПО НАПРАВЛЕНИЮ «АГРОИНЖЕНЕРИЯ»,

И РЕКОМЕНДУЕТСЯ НАУЧНО-МЕТОДИЧЕСКИМ СОВЕТОМ

ПО ТЕХНОЛОГИЯМ, СРЕДСТВАМ МЕХАНИЗАЦИИ И ЭНЕРГЕТИЧЕСКОМУ

ОБОРУДОВАНИЮ В СЕЛЬСКОМ ХОЗЯЙСТВЕ ФЕДЕРАЛЬНОГО УМО

ПО СЕЛЬСКОМУ, ЛЕСНОМУ И РЫБНОМУ ХОЗЯЙСТВУ

ДЛЯ ИСПОЛЬЗОВАНИЯ В УЧЕБНОМ ПРОЦЕССЕ.

В учебном пособии представлены курс лекций и практические работы по разделу «Линейные электрические цепи» дисциплины «Теоретические основы электротехники» с контрольными вопросами и задачами для самопроверки обучающихся.

УДК 621.317; ББК 31.21; ISВN 978-5-98914-201-9; 334 СТР.

ПО ВОПРОСАМ ПРИОБРЕТЕНИЯ ОБРАЩАТЬСЯ ПО АДРЕСУ: 150042, г. Ярославль, Тутаевское шоссе, 58, ФГБОУ ВО Ярославская ГСХА e-mail: e.bogoslovskaya@yarcx.ru 